OPEN ACCESS

Edited by:

Manuela Paechter,

University of Graz, Austria

Reviewed by:

Sarah E. Martiny,

UiT The Arctic University of Norway,

Norway

Thomas K. F. Chiu,

Faculty of Education, University of

Hong Kong, Hong Kong

*Correspondence:

Frances Hoferichter

frances.hoferichter@uni-greifswald.de

Diana Raufelder

diana.raufelder@uni-greifswald.de

Specialty section: This article was submitted to

STEM Education,

a section of the journal

Frontiers in Education

Received: 14 December 2018

Accepted: 13 February 2019

Published: 05 March 2019

Citation:

Hoferichter $F$ and Raufelder D (2019) Mothers and Fathers - Who Matters

for STEM Performance?

Gender-Specific Associations

Between STEM Performance, Parental

Pressure, and Support During Adolescence. Front. Educ. 4:14. doi: 10.3389/feduc.2019.00014

\section{Mothers and Fathers - Who Matters for STEM Performance? Gender-Specific Associations Between STEM Performance, Parental Pressure, and Support During Adolescence}

\author{
Frances Hoferichter* and Diana Raufelder* \\ Department School Pedagogics, Institute of Educational Science, Greifswald University, Greifswald, Germany
}

Research has shown that parental pressure is negatively whereas parental support is positively associated with various scholastic outcomes, such as school engagement, motivation, and achievement. However, only few studies investigate boys' and girls' perception of mother and father pressure/support in detail. This might be particularly essential when it comes to girls' and boys' achievement in STEM subjects, as girls and boys might profit differently from parental pressure/support regarding their achievement in STEM and vice versa. This study aims to shed light on this topic and explores potential within-and over time associations between students' perception of parental pressure/support and grades in mathematics and biology. Using self-report data from 1,088 8th grade students at T1 ( $M$ age $=13.70, S D=0.53,54 \%$ girls) from Brandenburg, Germany, multigroup cross-lagged models were conceptualized with Mplus. The results indicate that there are gender differences in the interplay of students' grades in mathematics, biology, and their perception of parental pressure and support: Whereas, mother support plays a central beneficial role for girls' achievement in STEM subjects as well as for the other parental variables over time, for boys mother support is negatively associated with math performance over time. Within-time associations further show that boys - in contrast to girls - do not benefit from any parental support regarding their performance in mathematics or biology. Finally, results suggest that the relationship between adolescents' STEM achievement and parental pressure/support is rather mono-directional than bi-directional over time.

Keywords: STEM performance, gender, parental support, parental pressure, secondary school

\section{INTRODUCTION}

The need for specialized labor in the field of science, technology, engineering, and mathematics (STEM) is constantly increasing as technology accompanies daily life. Despite this demand and efforts to inspire youth to follow a STEM career, girls are significantly under-represented in STEM subjects. According to the Trends in International Mathematics and Science Study (TIMSS), in 
most countries, boys represent the majority of students enrolling in advanced STEM courses in secondary education (Mullis et al., 2016). According to a recent report of the United Nations Educational Scientific Cultural Organization (2017), the gender gap becomes more apparent as the educational level increases and electives are available. In fact, at the age of 10-11 years, students are almost equally interested in STEM subjects, where by the age of 18 , only $33 \%$ of all boys and $19 \%$ of all girls who participated in this UK-based study were engaged in STEM (Kerney and YourLife Campaign, 2016). However, the gender gap regarding the attainment of STEM bachelor degrees after 4 years of college has been narrowing since 1977, where only 25 percent of all STEM degrees were awarded to women compared to the year 2000 in which 40 percent of all STEM degrees were obtained by women. Particularly in the fields of biology and agricultural science sex parity has been reached since the 1990s, whereas the gender gap is still striking in engineering, physical science, and math (National Science Board, 2014). Despite this trend of women receiving an equal number of degrees in the field of biology and agriculture, women prefer non-STEM degrees (Mann and DiPrete, 2013). As an explanation for the small number of girls involved in STEM, researcher mention varying interests of girls and boys (Su and Rounds, 2015), while girls excel in both language and math subjects compared to their male counterpart (Ceci et al., 2009), girls are more interested in tasks that promote symmetrical, quantitative, and verbal abilities (Su and Rounds, 2015). In this sense, the breadth-based model (Lubinski et al., 2001; Valla and Ceci, 2014) indicates that girls have broader career choices and choose careers in which they can apply people-related skills and verbal abilities, although having equal abilities to pursue a STEM career. In contrast, research on gender-specific socialization takes a different view, stating that girls' socialization presents the main factor for girls feeling inferior and less confident in STEM subjects, which are believed to represent masculine topics (Archer et al., 2013). Furthermore, stereotypes associated with STEM professions, e.g., working in STEM fields means being socially isolated, drive girls away from perusing a STEM career, as girls are socialized to interact with others, being social and pleasant (Reinking and Martin, 2018). In fact, children's believes about themselves, their ability and their attitude toward STEM education are strongly impacted by their parents as primary agent of socialization. This reasoning has been included in the General ExpectancyValue Model of Achievement Choices in which Eccles (2014) states that parents' specific beliefs and perceptions (e.g., affective reactions to child's performance, activity choice, competence and interest, parents' expectations for child's success, parents' perceptions of importance of activities and skills) as well as their specific actions and behaviors toward the child (e.g., advice, providing certain equipment, toys, and experiences for the child), impact children's motivation, activity choices, affect, interest, etc. toward STEM. This model provides a theoretical framework for a gendered bias emerging in STEM fields, despite the fact that boys and girls perform equally well in science. In line with this model, empirical work found that children had higher ability self-concepts and assigned a higher value to STEM subjects, when their parents showed positivity, co-activity, and school focused behaviors (Simpkins et al., 2015). In a qualitative study, in which Halim et al. (2018) interviewed parents of children who chose to pursue STEM education, the researchers found parental support and academic expectation to be common features of these parents. Hence, the investigated children who enrolled in STEM education had parents who supported their children in choosing STEM education, assisted them in science subjects, joined them in science-related activities and were concerned about their STEM related academic performance. Furthermore, parental emotional support and stimulating learning settings at home were mentioned to be relevant in choosing a career in STEM and develop an identity as scientist starting early in childhood (Buschor et al., 2014). In fact, support from parents varied considerably among students who maintained their interest in STEM throughout high school compared to those who lost interest in STEM (Aschbacher et al., 2010).

Although the role of parental support, expectation, and pressure have been identified as key factors for students to pursue a STEM career and to maintain interest in STEM (Dabney et al., 2013), only few studies take a more detailed view on the role of parents by examining the impact of mothers and fathers for girls and boys separately: Research shows that especially mother's beliefs about their daughter's ability in mathematics and science impact performance and career choices of girls (Gunderson et al., 2012; Rozek et al., 2015). Past research has predominantly investigated the role of mothers for the development of sons and daughters, while excluding the unique role of fathers. The reason for the lack of research on fathers' role regarding the upbringing of children may be its negative connotation and limitation to financial support (Hawkins and Dollahite, 1997; Marks and Palkovitz, 2004; Saracho and Spodek, 2008). The reason why fathers' role recedes in the background is fuelled by research findings indicating that it is the motherchild relationship which is characterized by low psychological distress (Mallers et al., 2010) and that mother's evaluate their behavior as more supportive toward their children compared to fathers (Fthenakis and Minsel, 2002). Examining the role of mothers and fathers for boys' and girls' career choices, Paa and Hawley McWhirter (2011) indicate, that in comparison to boys, girls perceived more positive feedback and autonomy support from their mother. In contrast, girls and boys equally perceived positive feedback and autonomy support from their father (Paa and Hawley McWhirter, 2011). Additionally, Fthenakis and Minsel (2002) found that fathers' of girls spend more time with their offspring compared to fathers' of boys, while fathers feel less disturbed by conflicts with girls compared to boys. Although research is limited, the few studies that focus on the role of mothers and fathers separately for boys and girls indicate that mother's and father's school related behavior are perceived differently by boys and girls. Fthenakis and Minsel (2002) found that boys compared to girls reported to receive more control and punishment concerning school issues. Similarly, in their study, Levpušček and Zupančič (2009) found that boys perceive significantly more father pressure than girls, while particularly fathers tend to differentiate between the upbringing of girls and boys (Lytton and Romney, 1991). Furthermore, past studies have mainly looked at how parental support/pressures impacts 
STEM performance, but not vice versa. Hence, it is not clear, how students' STEM performance impacts their perception of parental support and pressure (bi-directional).

Based on these gender specific findings, the recent study takes a detailed view on the role of mother's and father's support and pressure for boys' and girls' academic performance in STEM subjects such as mathematics and biology. Mathematics was chosen as there is a sex disparity in the fields of engineering, physical science and math. In contrast, biology was chosen as bachelor's degrees are equally attained by male and female students. By choosing a domain that is over-presented by males (math) and a domain in which males and females are involved equally (biology), the study aims at shedding light on the differential role of mothers and fathers for girls' and boys' STEM performance and vice versa (bi-directional) by using a crosslagged-panel design to identify potential factors that contribute or hinder academic success in the field of STEM and in turn serve as template for further research and intervention involving both mothers and fathers.

\section{HYPOTHESIS}

In order to test how mother's and father's pressure and support at Time 1 and 2 as well as STEM performance at Time 1 and 2 would relate to each other within and over time for boys and girls, a multigroup cross-lagged model was designed. In particular, the following hypotheses were tested:

Hypothesis I: Adolescent girls and boys differ regarding their perceived parental pressure/support associated with their grades in two STEM subjects (i.e., mathematics and biology) at the beginning of 8th grade and 1.5 years later at the end of 9 th grade (within-time associations).

Hypothesis II: Adolescent girls and boys differ regarding the associations between their perceived parental pressure/support and their grades in two STEM subjects (i.e., mathematics and biology) and vice versa during the beginning of 8 th to the end of 9th grade (over time associations).

\section{METHODS}

\section{Participants and Procedure}

This two-wave study is based on data from 1,088 8th grade students at Time 1 (T1) $\left(M_{\text {age }}=13.70\right.$, aged $12-15$ years, $S D$ $=0.53,54 \%$ girls), who were at the end of 9th grade at Time $2(\mathrm{~T} 2)\left(N=845 ; M_{\text {age }}=14.86\right.$, aged 13-17 years, $S D=0.57$, $55 \%$ girls). The participants were recruited from 23 randomly selected public secondary schools out of a pool of 124 public secondary schools in the federal state of Brandenburg, Germany. In order to provide a representative sample for the federal state of Brandenburg, five of the 23 schools were located in the biggest cities of the state (Potsdam, Cottbus, Frankfurt Oder, Brandenburg, and Prenzlau), while the other 18 were located in rural areas. The data collection took place in the autumn term 2011 (T1) and the spring term 2013 (T2). From T1 to T2 the dropout rate amounts $22.33 \%$ of participating students. The study focuses on this specific age group, as some studies indicate an achievement drop in school during this time period (Dohn, 1991; Wijsman et al., 2016). Initially, (1) written permission of the ethical committee of the Hoorn, Youth, and Sport (MBJS) of Brandenburg, (2) school consensus, and (3) both parents' and students' written and informed consensus was obtained. Before students filled in the paper-pencil questionnaire, experienced research instructors informed about voluntary participation and confidential treatment of responses. As there is only a small amount of ethnic diversity in Brandenburg (2.6\%), data on ethnicity was not collected. The German law prohibits collecting data from a third party (i.e., asking students about their parents income or school graduation), students' socio-economic status could not be assessed.

\section{Measures}

All self-report measures used in this study are well-established instruments for German-speaking students. The reported reliability values are based on the current sample.

STEM grades were addressed by students' self-reported grades on their two most recent report cards in Mathematics $\left(\alpha \mathrm{T} 1_{\text {girls }}=\right.$ $0.87 ; \alpha \mathrm{T} 2$ girls $=0.87 ; \alpha \mathrm{T} 1_{\text {boys }}=0.84 ; \alpha \mathrm{T} 2$ boys $\left.=0.84\right)$ and Biology $\left(\alpha \mathrm{T} 1_{\text {girls }}=0.83 ; \alpha \mathrm{T} 2\right.$ girls $=0.83 ; \alpha \mathrm{T} 1_{\text {boys }}=0.84$; $\alpha \mathrm{T} 2$ boys $=0.84$ ). Grades range from 1 ("very good") to 6 ("insufficient") in the German school system. For the sake of clarity, all grades were reverse-coded in the present study, such as a high score represents high achievement.

Parental Pressure was measured with the "Zurich Questionnaire of Educational Behavior" [Züricher Kurzfragebogen zum Erziehungsverhalten] (ZKE) developed by Reitzle et al. (2001) on a 4-point Likert scale from 1 ("not true at all") to 4 ("totally true"). The subscales father pressure $\left(\alpha \mathrm{T} 1_{\text {girls }}=0.79 ; \alpha \mathrm{T} 2\right.$ girls $=0.83 ; \alpha \mathrm{T} 1_{\text {boys }}=0.80 ; \alpha \mathrm{T} 2$ boys $=$ $0.80)$ and mother pressure $\left(\alpha \mathrm{T} 1_{\text {girls }}=0.77 ; \alpha \mathrm{T} 2\right.$ girls $=0.80$; $\left.\alpha \mathrm{T}_{\text {boys }}=0.78 ; \alpha \mathrm{T} 22_{\text {boys }}=0.79\right)$ consist of six items each (e.g., "My mother/father pushes me to work harder in school" or "My mother/father expects that I do well in school").

Parental Support was also measured with the "Zurich Questionnaire of Educational Behavior" (ZKE) (Reitzle et al., 2001). The subscales father support $\left(\alpha \mathrm{T} 1_{\text {girls }}=0.92 ; \alpha \mathrm{T} 2\right.$ girls $=0.92 ; \alpha \mathrm{T}_{\text {boys }}=0.91 ; \alpha \mathrm{T} 2$ boys $\left.=0.90\right)$ and mother support $\left(\alpha \mathrm{T} 1_{\text {girls }}=0.90 ; \alpha \mathrm{T} 2\right.$ girls $=0.91 ; \alpha \mathrm{T} 1_{\text {boys }}=0.88$; $\alpha \mathrm{T} 2$ boys $=0.88$ ) consist of 10 items each (e.g., "If I do not understand something, my mother/father explains it to me" or "My mother/father is studying with me").

\section{Statistical Analyses}

Initially, random parcels for each latent variable were built due to the large amount of single items per variable, which is a common procedure in psychological research (Nasser and Wisenbaker, 2003). Accordingly, each latent variable in the present study consists of three parcels. Little et al. $(2002,2013)$ list various reasons why parceling can be beneficial compared to using single items regarding psychometrics, model estimation, and fit characteristics. In contrast to item-level data, parcels show higher reliability, higher ratio of common-to-unique factor variance, greater communality, lower likelihood of distributional violations as well as more, tighter, and more-equal intervals, 
fewer parameter estimates, reduced sources of sampling error, lower indicator-to-sample size ratio as well as lower likelihood of correlated residuals and dual factor loadings.

Furthermore, measurement invariance over time as a precondition of cross-lagged panel design was tested for all variables used in this study. In the next step, three multigroup cross-lagged models were conceptualized: A less-restricted model (free parameters across girls and boys), a semi-restricted model (equal factor loadings, free thresholds, and free regression coefficients among girls and boys) and a more-restricted model (equal factor loadings, equal thresholds and equal regression coefficients across both groups). The less-restricted model was compared to the semi-restricted model to test for measurement invariance between the groups (i.e., girls and boys) by using $\chi^{2}$-difference test (Yuan and Bentler, 2004). Subsequently, the semi-restricted model (with gender differences) was compared to a more-restricted model (considering no gender differences) in order to test which model would fit the data best.

All analyses were conducted with the "type is complex" command in Mplus to account for the nested structure of the data (students nested in classes) (Asparouhov, 2005). Four primary fit indices were used to determine model fit ( $\mathrm{Hu}$ and Bentler, 1999): Chi-Square Test of Model Fit $\left(\chi^{2}\right)$, Root Mean Square Error of Approximation (RMSEA), Comparative Fit Index (CFI) and Standardized Root Mean Square Residuals (SRMR). Little's MCAR test $\left(\chi^{2}=268.07 ; d f=233 ; p>0.05\right)$ revealed that missing data was completely at random, which allows using full-information maximum likelihood (FIML) estimation.

\section{RESULTS}

\section{Bivariate Correlations and Descriptive Statistics}

Table 1 presents the gender-specific bivariate correlations and descriptive statistics calculated with IBM SPSS software (see Table 1).

\section{Multigroup Cross-Lagged Panel Design}

Initially, measurement invariance for the variables of interest was tested stepwise over time (see Table 2). As shown in Table 2 strong factorial invariance is held for all latent variables, which is a precondition for cross-lagged panel design.

To test our hypotheses, three multi-group cross-lagged models (less-restricted model, semi-restricted model, morerestricted model) were conceptualized with Mplus (Muthén and Muthén, 1998-2013). All models included (a) autoregressive paths between the same variable at T1 and T2, (b) cross-lagged paths between a variable and each other variables over time, and (c) within-time covariances between all variables at T1 as well as within-time covariances between all variables at T2. To test for measurement invariance between the groups (i.e., girls and boys) a less-restricted model with all free parameters was conceptualized in a first step $\left[\chi_{(564)}^{2}=1658.82, p<0.001\right.$; CFI $=0.92$; RMSEA $=0.06(0.06-0.06)$, SRMR $=0.06]$. This model was compared with the semi-restricted model $\left[\chi_{(596)}^{2}=1660.37\right.$, $p<0.001$; CFI $=0.92$; RMSEA $=0.06(0.05-0.06)$, SRMR $=0.07]$ with equal factor loadings, free thresholds, and free regression coefficients among boys and girls by using the $\chi^{2}$-difference test $\left[\chi_{(32)}^{2}=5.71, p>0.05\right]$ (Satorra and Bentler, 2001). The test indicated that the semi-restricted model was favored to the less-restricted model, which confirms measurement invariance between girls and boys. In a next step, a more restricted model $\left[\chi_{(641)}^{2}=1731.80, p<0.001 ; \mathrm{CFI}=0.92\right.$; $\mathrm{RMSEA}=0.06$ (0.05-0.06), SRMR $=0.08]$ with equal factor loadings, equal thresholds and equal regression coefficients across both groups was conceptualized. Again, the $\chi^{2}$-difference test $\left[\chi_{(45)}^{2}=76.59\right.$, $p<0.05$ ] (Satorra and Bentler, 2001) between the semi-restricted and the more restricted model was conducted, implying that the semi-restricted model reflects the data better than the more restricted model. This means that different patterns for girls and boys are exhibited in the cross-lagged model.

\section{Model Girls}

\section{Auto-Regressive Effects Over Time}

All auto-regressive paths between each variable at T1 and T2 were found to be significant, which supports the stability of the constructs over time (see Figure 1).

\section{Cross-Lagged Effects Over Time}

Eight cross-lagged effects were found to be significant over time: Mother pressure at T1 negatively predicts the grades in mathematics at T2, whereas mother support at T1 negatively predicts mother pressure at $\mathrm{T} 2$ and positively predicts father support at T2, as well as girls' grades in mathematics and biology at T2. Father support at T1 positively predicts mother pressure at T2. Furthermore, the grades in mathematics at T1 positively predict the girls' grades in biology at T2 and vice versa (see Figure 1).

\section{Covariances Within-Time}

At T1 all covariances except for the association between mother support and father pressure were found to be significant: There was a positive association between mother support and father support $(r=0.19, p<0.001)$, between mother support and girls' grades in mathematics $(r=0.06, p<0.01)$ and biology $(r=0.07, p<0.001)$. In turn, there was a negative association between mother pressure and mother support $(r=-0.08, p$ $<0.001)$, father support and mother pressure $(r=-0.05, p$ $<0.05)$ as well as between mother pressure and girls' grades in both mathematics $(r=-0.10, p<0.01)$ and biology $(r=-0.11, p<0.001)$. The association between mother pressure and father pressure $(r=0.34, p<0.001)$ was positive. Furthermore, there was a positive relation between father support and both girls' grades in mathematics $(r=0.07, p<0.01)$ and biology $(r=0.07, p<0.01)$, whereas the association between father pressure and girls' grades in mathematics $(r=$ $-0.10, p<0.01)$ and biology $(r=-0.08, p<0.01)$ were negative. Finally, the relation between father support and father pressure was positive $(r=0.09, p<0.01)$ as well as the relation between girls' grades in mathematics and biology $(r=0.31$, $p<0.001)$.

At T2, only eight covariances were found to be significant: The association between mother pressure and father pressure 
TABLE 1 | Gender-specific means, standard deviations, and intercorrelations of the constructs.

\begin{tabular}{|c|c|c|c|c|c|c|c|c|c|c|c|c|c|c|}
\hline & MP T2 & FP T1 & FP T2 & MS T1 & MS T2 & FS T1 & FS T2 & Ma T1 & Ma T2 & Bio T1 & Bio T2 & $\boldsymbol{R}$ & $M$ & $S D$ \\
\hline \multicolumn{15}{|l|}{ GIRLS } \\
\hline MP T1 & $0.57^{\star \star}$ & $0.51^{\star \star}$ & $0.28^{\star \star}$ & $-0.11^{\star \star}$ & $-0.10^{\star}$ & -0.00 & -0.07 & $-0.12^{\star \star}$ & $-0.20^{\star \star}$ & $-0.13^{\star \star}$ & $-0.19^{\star \star}$ & $1-4$ & 2.50 & 0.66 \\
\hline MP T2 & - & $0.30^{\star \star}$ & $0.49^{\star \star}$ & -0.08 & -0.06 & 0.05 & 0.04 & -0.06 & $-0.21^{\star \star}$ & $-0.10^{\star}$ & $-0.19^{\star \star}$ & $1-4$ & 2.35 & 0.68 \\
\hline FP T1 & & - & $0.54^{\star \star}$ & 0.06 & -0.02 & $0.22^{\star \star}$ & $0.13^{\star \star}$ & $-0.14^{\star \star}$ & $-0.18^{\star \star}$ & $-0.10^{\star}$ & -0.09 & $1-4$ & 2.18 & 0.66 \\
\hline FP T2 & & & - & -0.05 & -0.06 & $0.10^{*}$ & $0.18^{\star \star}$ & $-0.15^{\star \star}$ & $-0.28^{\star \star}$ & $-0.13^{\star \star}$ & $-0.26^{\star *}$ & $1-4$ & 2.14 & 0.72 \\
\hline FS T1 & & & & & & - & $0.64^{\star \star}$ & $0.13^{\star \star}$ & $0.13^{\star \star}$ & $0.16^{\star \star}$ & $0.11^{*}$ & $1-4$ & 2.91 & 0.73 \\
\hline FS T2 & & & & & & & - & $0.12^{* \star}$ & $0.14^{\star \star}$ & $0.13^{\star \star}$ & $0.11^{*}$ & $1-4$ & 2.77 & 0.75 \\
\hline Ma T1 & & & & & & & & - & $0.66^{\star \star}$ & $0.53^{\star \star}$ & $0.39^{\star \star}$ & $1-6$ & 4.30 & 0.79 \\
\hline Ma T2 & & & & & & & & & - & $0.47^{\star \star}$ & $0.52^{\star \star}$ & $1-6$ & 4.13 & 0.87 \\
\hline Bio T1 & & & & & & & & & & - & $0.57^{\star \star}$ & $1-6$ & 4.75 & 0.74 \\
\hline MP T2 & - & $0.33^{\star \star}$ & $0.58^{\star \star}$ & 0.07 & $0.16^{\star \star}$ & 0.07 & $0.15^{\star \star}$ & $-0.17^{\star \star}$ & $-0.23^{\star \star}$ & $-0.14^{\star \star}$ & $-0.12^{*}$ & $1-4$ & 2.52 & 0.68 \\
\hline FP T1 & & - & $0.51^{\star \star}$ & $0.15^{\star \star}$ & $0.11^{*}$ & $0.37^{\star \star}$ & $0.19^{\star \star}$ & $-0.17^{\star \star}$ & $-0.17^{\star \star}$ & $-0.13^{\star \star}$ & $-0.16^{\star \star}$ & $1-4$ & 2.41 & 0.69 \\
\hline FP T2 & & & - & -0.00 & $0.14^{\star \star}$ & $0.12^{\star}$ & $0.29^{\star \star}$ & $-0.25^{\star \star}$ & $-0.23^{\star \star}$ & $-0.21^{\star \star}$ & $-0.17^{\star \star}$ & $1-4$ & 2.34 & 0.75 \\
\hline MS T1 & & & & - & $53^{* *}$ & $0.53^{\star \star}$ & $0.27^{\star \star}$ & -0.08 & $-0.13^{*}$ & 0.09 & $0.11^{*}$ & $1-4$ & 2.97 & 0.59 \\
\hline MS T2 & & & & & - & $0.29^{\star \star}$ & $0.52^{\star \star}$ & -0.02 & -0.03 & 0.09 & 0.09 & $1-4$ & 2.75 & 0.61 \\
\hline FS T1 & & & & & & - & $0.52^{\star \star}$ & 0.01 & -0.03 & $0.14^{\star \star}$ & 0.07 & $1-4$ & 2.95 & 0.67 \\
\hline FS T2 & & & & & & & - & -0.02 & 0.01 & 0.09 & 0.02 & $1-4$ & 2.76 & 0.67 \\
\hline Ma T1 & & & & & & & & - & $0.65^{\star \star}$ & $0.49^{\star \star}$ & $0.35^{\star \star}$ & $1-6$ & 4.48 & 0.81 \\
\hline Мa Т2 & & & & & & & & & - & 0.38 & $0.41^{\star \star}$ & $1-6$ & 4.11 & 0.88 \\
\hline Bio T1 & & & & & & & & & & - & $0.62^{\star \star}$ & $1-6$ & 4.55 & 0.85 \\
\hline Bio T2 & & & & & & & & & & & - & $1-6$ & 4.46 & 0.83 \\
\hline
\end{tabular}

Correlations are standardized coefficients; ${ }^{*} p<0.05,{ }^{* *} p<0.01$; MP, Mother Pressure; FP, Father Pressure; MS, Mother Support; FS, Father Support; Ma, math grade; Bio, biology grade; Grades in German school system range from 1 = "very good" to 6 = "insufficient"-for sake of clarity, all grades were reverse-coded. T1, Time 1 (8th grade); T2, Time 2 (9th grade); R, Range; $M$, Mean.

TABLE 2 | Model fit indices for measurement invariance testing over time and results of $\chi^{2}$-difference test with scaling correction using MLR estimator and "type is complex" in Mplus.

\begin{tabular}{|c|c|c|c|c|c|c|c|c|c|c|}
\hline Model & $x^{2}$ & df & $p$ & RMSEA & $90 \% \mathrm{Cl}$ & CFI & SRMR & $\Delta \chi^{2}$ & $p$ & $\Delta$ df \\
\hline Model 0 & 1444.79 & 391 & $<0.001$ & 0.05 & $0.05-0.05$ & 0.93 & 0.06 & - & - & - \\
\hline Model 1 & 1453.98 & 401 & $<0.001$ & 0.05 & $0.05-0.05$ & 0.93 & 0.06 & 6.09 & $>0.05$ & 10 \\
\hline Model 3 & 1482.93 & 417 & $<0.001$ & 0.05 & $0.05-0.05$ & 0.93 & 0.06 & 15.38 & $<0.05$ & 6 \\
\hline
\end{tabular}

Model 0 , no constraints but configural invariance; Model 1, loadings invariant across time (weak invariance); Model 2, loadings and intercepts invariant across time (strong invariance); Model 3, measurement model including time invariance restriction (strict invariance). Bold values indicate the best model fit.

$(r=0.20, p<0.001)$ was positive, whereas the relation between mother pressure and girls' grades in mathematics $(r$ $=-0.04, p<0.05)$ was negative. The association between father support and father pressure $(r=0.05, p<0.05)$ and between father support and mother support $(r=0.08$, $p<0.001)$ were positive. Furthermore, both the relation between girls' grades in mathematics and father pressure $(r$ $=-0.09, p<0.001)$ were negative as well as the association between girls' grades in biology and father pressure $(r=$ $-0.10, p<0.001)$. In turn, the association between girls' grades in mathematics and mother support $(r=0.04, p<$
0.01) was positive. Finally, the relation between girls' grades in mathematics and biology $(r=0.11, p<0.001)$ was still positive.

The association between mother support and mother pressure, between father support and mother pressure, between girls' grades in mathematics and father support, between girls' grades in biology and mother pressure, between girls' grades in biology and mother support as well as between girls' grades in biology and father support were no longer significant. Finally, the relation between mother support and father pressure was still not significant. 


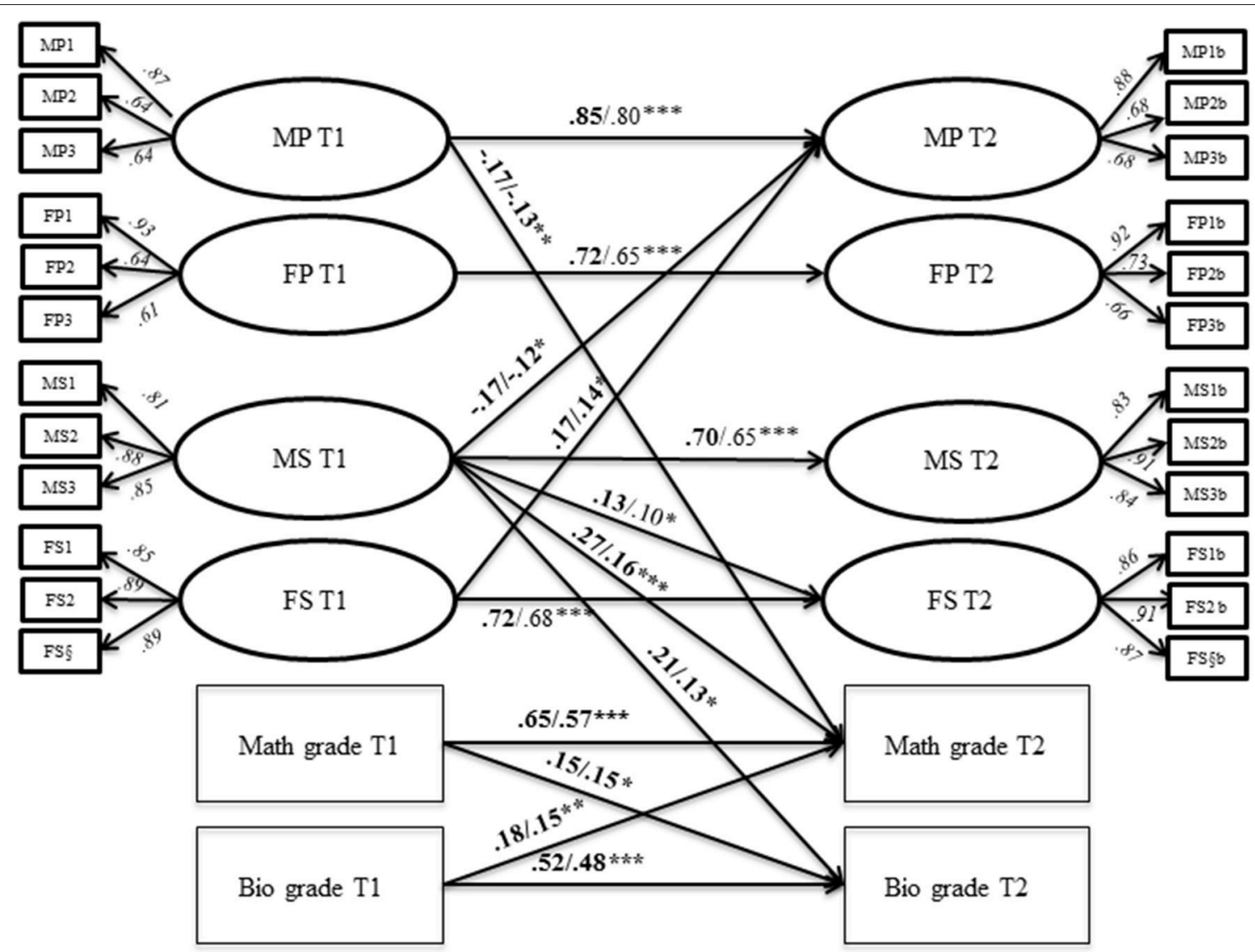

FIGURE 1 | Multigroup cross-lagged model for girls. MP, Mother Pressure; FP, Father Pressure; MS, Mother Support; FS, Father Support; T1, Time 1 (8th grade); T2, Time 2 (9th grade); Factor loadings are shown as standardized coefficients. For sake of clarity, solely significant autoregressive and cross-lagged paths are shown in the figure: First position indicates unstandardized coefficients $(B)$, second position standardized coefficients ( $\beta$ ). In order to obtain a clearly arranged figure, the covariances between all variables at $\mathrm{T} 1$ and between all variables at $\mathrm{T} 2$ are not shown in the figure, but reported in the manuscript.

\section{Model Boys}

\section{Auto-Regressive Effects Over Time}

All auto-regressive paths between each variable at T1 and T2 were found to be significant, which support the stability of the constructs over time (Figure 2).

\section{Cross-Lagged Effects Over Time}

Three cross-lagged effects were found to be significant over time: Mother pressure at T1 positively predicts father pressure at T2, whereas mother support negatively predicts boys' grades in mathematics. Finally, the grades in biology at T1 positively predict boys' grades in mathematics at $\mathrm{T} 2$, but not vice versa (Figure 2).

\section{Covariances Within-Time}

At T1 all covariances except for four associations (between mother support and both boys' grades in mathematics and biology as well as between father support and both boys' grades in mathematics and biology) were found to be significant: There was a positive association between mother support and father support $(r=0.16, p<0.001)$, between mother support and father pressure $(r=0.05, p<0.05)$ - which was not significant for girls-and between mother pressure and father support ( $r=$ $0.06, p<0.05)$ as well as between mother pressure and mother support $(r=0.04, p<0.05)$, whereas the latter association was negative for girls. Furthermore, the relation between mother pressure and both boys' grades in both mathematics $(r=-0.15$, $p<0.001)$ and biology $(r=-0.11, p<0.001)$ were negative. The association between mother pressure and father pressure $(r$ $=0.36, p<0.001)$ was positively. Furthermore, the association between father pressure and boys' grades in mathematics $(r=$ $-0.11, p<0.001)$ and biology $(r=-0.11, p<0.001)$ were negatively. Finally, the relation between father support and father pressure was positive $(r=0.17, p<0.001)$ as well as the relation between boys' grades in mathematics and biology $(r=0.34$, $p<0.001)$.

At T2, eight covariances were found to be significant: In contrast to the girls, the association between mother support and mother pressure $(r=0.04, p<0.05)$ as well as between mother support and father pressure $(r=0.07, p<0.001)$ was still positively significant. Furthermore, the relation between mother pressure and father pressure $(r=0.22, p<0.001)$, as well as the relation between father support and father pressure $(r=0.12, p<$ $0.001)$ and between father support and mother support $(r=0.12$, 


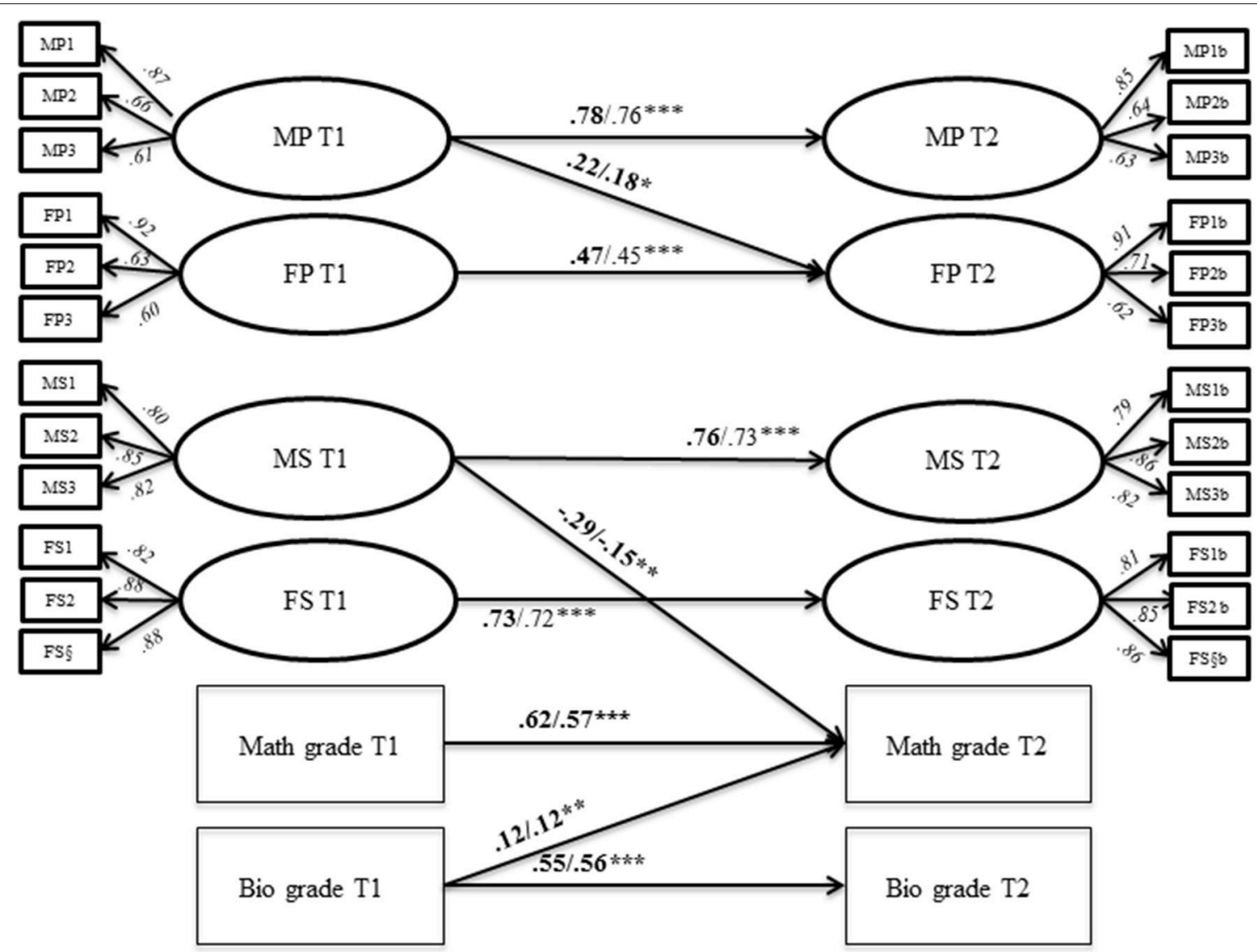

FIGURE 2 | Multigroup cross-lagged model for boys. MP, Mother Pressure; FP, Father Pressure; MS, Mother Support; FS, Father Support; T1, Time 1 (8th grade); T2, Time 2 (9th grade); Factor loadings are shown as standardized coefficients. For sake of clarity, solely significant autoregressive and cross-lagged paths are shown in the figure: First position represents unstandardized coefficients $(B)$, second position standardized coefficients $(\beta)$. In order to obtain a clearly arranged figure, the covariances between all variables at T1 and between all variables at T2 are not shown in the figure, but reported in the manuscript.

$p<0.001)$ was positively significant. In turn, the relation between boys' grades in mathematics and mother pressure was negative $(r=-0.06, p<0.05)$. Finally, boys' grades in mathematics and biology were positively associated $(r=0.10, p<0.01)$.

The association between father support and mother pressure, between boys' grades in mathematics and father support, boys' grades in mathematics and pressure, boys' grades in mathematics and mother support as well as between boys' grades in biology and all parental variables were not significant.

\section{DISCUSSION}

This study aimed to shed light on potential gender-specific differences in the within- and over time associations between adolescents' perception of parental pressure/support and their grades in mathematics and biology.

In line with hypothesis I we found that girls and boys differ regarding their perceived parental pressure/support associated with their grades in mathematics and biology at the beginning of 8th grade and 1.5 years later at the end of 9th grade (within-time associations). While for girls, mother and father support in 8 th grade were associated with better grades in math and biology, for boys, neither mother nor father support were significantly related to their STEM performance. Hence, boys do not profit from mother/father support regarding their academic performance in math and biology but may be interested in STEM independent of parental behavior (Su and Rounds, 2015). Also, it can be assumed that boys are impacted by their peer group, rather than their parents. Various studies show that students' motivation and involvement in school are influenced by their peers (Raufelder et al., 2013; van Hoorn et al., 2014). Robnett and Leaper (2013) found that students were more likely to be interested in pursuing a STEM career if their peer group valued STEM, even after controlling for individual grades, values, and expectations.

In contrast to boys, girls' performance in math and biology was related to parental support. Hence, the results indicate that (1) parental behavior is perceived differently by girls and boys and/or (2) parents act differently toward their male vs. female offspring. In support of these arguments, Fthenakis and Minsel (2002) found that fathers' of daughters spend more time with their offspring compared to fathers' of sons, which could explain why father support is related to better STEM performance among girls, but not among boys. Additionally, Paa and Hawley 
McWhirter (2011) found that particularly girls received more positive feedback and autonomy from their mother.

Compared to the role of mothers, the impact of fathers on their offspring seems much harder to grasp. In past research the father figure was described to be limited to financial support, inadequate, or absent fathering (Hawkins and Dollahite, 1997; Marks and Palkovitz, 2004). The father figure implies rather negative connotations, or is insufficiently conceptualized, which becomes clear in the work "Fathers: the "invisible" parents" (Saracho and Spodek, 2008). However, while the gender gap between mothers and fathers is quite persistent over time regarding housework and child rearing (Kan et al., 2011), more recent work characterizes the father as the "working caring-dad" whose role comprises more than a bread-winning function as he is ready to sacrifice - at least in part and among older fathers-his career for children (Fthenakis and Minsel, 2002). In the current study, the father comes into play, when boys and girls perceive his pressure, which is related to lower STEM performance in math and biology for girls in 8 and 9th grade and for boys in grade 8 . The challenge of characterizing the role of fathers is indicated by the finding that both girls and boys report the more father support they receive also the more pressure they perceive, which is consistent across time. Hence, father support cannot be described as solely positive while father pressure cannot be described as solely negative for boys' and girls' STEM performance. In fact, although parental support and pressure are separate concepts, children perceive them as overlapping as part of general parenting behavior. While pressure is described as behavior indicating expectations that are high, unlikely or even impossible to attain, this nominal definition depends on the child's perception of parental pressure and support (Leff and Hoyle, 1995). Besides the positive association between father support and pressure, mother support and pressure was also positively associated for boys in both grades 8 and 9. Contrary, girls who receive mother support, receive less mother pressure in 8th grade. Interestingly, boys who receive mother support also receive less father pressure, while for girls there was no such significant association. In the case of boys, the mother might compensate for the father pressure by supporting her son. It was found that fathers feel more disturbed with respect to conflicts and trouble by their sons, compared to daughters (Fthenakis and Minsel, 2002). While, a diary study indicates that the relationship with mothers is related to lower psychological distress for both boys and girls (Mallers et al., 2010). In line with this finding, according to a self-report study, on average, mothers evaluate themselves as more supportive toward their children compared to fathers (Fthenakis and Minsel, 2002), while fathers show more control and punishment regarding schoolwork toward their sons compared to daughters. In general, the findings show that for both boys and girls, the association between parental support /pressure and STEM performance is higher in grade 8 compared to grade 9. This finding indicates that parental pressure and support has more impact at the age of about 13 compared to the age of about 15 , as parents become gradually less important across the development of youth (Erikson, 1993; Eccles, 2007) while peers and their values, activities, and attitudes become more important (Leff and Hoyle, 1995; van Hoorn et al., 2014).
Investigating over time associations between mother/father support/pressure, math and biology performance, all auto-regressions were significant from grade 8 to grade 9, indicating the reliability of the constructs. Furthermore, hypothesis II was partially confirmed, as girls and boys varied in their perception of mother/father support/pressure related to their STEM performance in math and biology over time, but not vice versa. In other words, the relation between parental support/pressure and student's STEM performance seems to be rather mono-directional, such as parental support/pressure predicts STEM performance, but not vice versa. Future longitudinal studies with more than two waves are necessary to test a potential causal ordering of the variables.

For girls, mother support in grade 8 was related to better math and biology performance in grade 9 , while mother pressure in grade 8 was related to lower math performance in grade 9 , but not to biology performance. Hence, girls' biology performance seems independent of mother pressure, indicating that girls may have stable interests in biology, which is not per se a masculine STEM subject, and their peer group may value or engage in biology at school. In fact, Leaper et al. (2011) found that adolescent girls' motivation in STEM courses was positively related with peer support over the school years. These interpretations may give an explanation why females and males are equally engaged in biology and agricultural studies.

For boys, only mother support in grade 8 was related to low math performance in grade 9. Hence, while girls perceive mother support as helpful for better STEM performance, boys perceive mother support as debilitating their performance in math. This finding indicates that boys may receive mother support as pressure related to high expectations, which in turn hinder boys' STEM performance.

Contrary to the impact of mothers, father support or pressure was not related to girls' and boys' STEM performance over time. These findings underline the impact of mothers for students' performance in STEM, which have been investigated in various studies (Paa and Hawley McWhirter, 2011; Gunderson et al., 2012; Rozek et al., 2015). In fact, compared to fathers, it is mostly the mother who is involved in and concerned with school and family issues (Winquist Nord and West, 2001), which might be the reason why mothers' school related behavior impacts both boys' and girls' STEM performance.

As boys' STEM performance is barely impacted by parental behavior, their academic performance might be related to other factors outside the family, such as interest (Su and Rounds, 2015), or boys might just live up to the stereotype that STEM subjects are masculine, confirming their interest even more (Archer et al., 2013). In fact, compared to boys, it is much harder to involve and maintain the interest of girls in STEM. In this sense, the current study indicates that girls profit from mother support and in contrast suffer from mother pressure regarding their STEM performance. Hence, mothers should be aware of their schoolrelated behavior, particularly exerting pressure as it inhibits girl's STEM performance as well as giving support to their male offspring, which in fact is perceived as pressure. Furthermore, the results of the study show that boys' and girls' STEM performance in grade 8 does not impact the school related behavior of mothers 
and fathers 1.5 years later. Hence, it is the differentiated parental behavior that impacts STEM performance and not vice versa, i.e., STEM performance in grade 8 does not impact mothers' and fathers' support/pressure in 9th grade.

Overall, the results adhere to the General ExpectancyValue Model of Achievement Choices (Eccles, 2014), as results indicate that father and mother behavior impact boys' and girls' performance in STEM. However, this model does not take into account the specific and different role of mothers and fathers regarding the STEM performance of boys and girls. To further analyze the impact of maternal and paternal behavior, future studies should include information on parental time spent with children, gender attitudes or distribution of domestic tasks and child care. In sum, this study indicates that mother support plays an essential but different role for boys' and girls' STEM performance. While mother support should further be encouraged for girls, the support directed toward boys should be reconsidered as mother support seems to be accompanied by expectations or pressure. Furthermore, mother's pressure inhibits STEM performance among girls and should therefore be reduced or eliminated in the school-related behavior of mothers. The results also show that the father does not have a long lasting effect (from grade 8 to grade 9) on neither boys' nor girls' STEM performance. However, cross-sectionally father's pressure is related to low STEM performance for both boys and girls. Therefore, similarly to mother's pressure, the father should also be urged to eliminate his pressure toward his offspring regarding school performance. Additionally, fathers should be encouraged to support their sons and daughters in school related issues and engage in school work, conversations about science, and in whatever concerns their offspring in order to build confidence in the father-child relationship and support boys' and girls' development positively. Parent-child interventions may help parents to reflect and find their role regarding their scholastic behavior as well as give parents the opportunity to communicate with their children about the child's needs, fears, and hopes regarding their academic performance in STEM. Furthermore, gender-specific parent-child activities in school could be added to existing models, such as the American model of family-school partnerships (Epstein, 1995), which helps parents to recognize the value of their contributions to schooling practices and foster students' academic involvement (Nawrotzki, 2012).

\section{REFERENCES}

Archer, L., DeWitt, J., Osborne, J., Dillon, J., Willis, B., and Wong, B. (2013).'Not girly, not sexy, not glamorous': primary school girls'and parents'constructions of science aspirations. Pedag. Cult. Soc. 21, 171-194. doi: 10.1080/14681366.2012.748676

Aschbacher, P., Li, E., and Roth, E. (2010). Is science me? High school students' identities, participation and aspirations in science, engineering, and medicine. J. Res. Sci. Teach. 47, 564-582. doi: 10.1002/tea. 20353

Asparouhov, T. (2005). Sampling weights in latent variable modeling. Struct. Equat. Model. 12, 37-41. doi: 10.1073/pnas. 0910967107

Buschor, C. B., Berweger, S., Keck Frei, A., and Kappler, C. (2014). Majoring in STEM - What accounts for women's career decision making? A mixed methods study. J. Educ. Res. 107, 167-176. doi: 10.1080/00220671.2013.788989

Ceci, S. J., Williams, W. M., and Barnett, S. M. (2009). Women's underrepresentation in science: Sociocultural and biological

\section{Strength, Limitations, and Future Directions}

Strength: Girls and boys perception of pressure and support from both mothers and fathers was considered separately. Furthermore, results are based on data from a large sample with two waves (beginning of 8 th grade and end of 9 th grade) grasping a longer period during adolescence.

Limitations: Self-reported grades are rather a weak indicator of students' achievement in STEM. However, we used selfreport measures as we were particularly interested in students' perception of their parents' support and pressure. Future studies are warranted, which use more detailed instruments of girls' and boys' STEM achievement and additionally consider associated concepts, such as subject-related interest and motivation.

Future Directions: Results suggest that the relationship between adolescents' STEM achievement and parental pressure/support is rather mono-directional than bidirectional over time. Future longitudinal studies with several measurement points might identify a potential causal order of the variables. In addition, variables such as parental time spent with children, gender attitudes or distribution of domestic tasks and child care should be included as moderators in future studies.

\section{DATA AVAILABILITY}

The datasets generated for this study are available on request to the corresponding author.

\section{AUTHOR CONTRIBUTIONS}

FH wrote the main part of the paper. DR did the statistical analyses and wrote the method and results section.

\section{ACKNOWLEDGMENTS}

The research reported in this paper was supported by a grant from The Volkswagen Foundation (Schumpeter Fellowship II/84 452). The authors would like to thank the principals, teachers, and students for their cooperation in making these studies possible.

considerations. Psychol. Bull. 135, 218-261. doi: 10.1037/a00 14412

Dabney, K. P., Chakraverty, D., and Tai, R. H. (2013). The association of family influence and initial interest in science. Sci. Educ. 97, 395-409, doi: $10.1002 /$ sce. 21060

Dohn, H. (1991). Dropout in the Danish high school (gymnasium). An investigation of psychological, sociological and pedagogical factors. Int. Rev. Educ. 37, 415-428. doi: 10.1007/BF00597619

Eccles, J. S. (2007). "Families, schools, and developing achievement-related motivations and engagement," in Handbook of Socialization: Theory and Research, eds J. E. Grusec and P. D. Hastings (New York, NY: Guilford Press), 665-691.

Eccles, J. S. (2014). Gendered socialization of STEM interests in the family. Int. J. Gender Sci. Technol. 7, 116-132.

Epstein, J. L. (1995). School/family/community partnerships: caring for the children we share. Phi Delta Kappan 76, 702-712. doi: $10.1177 / 003172171009200326$ 
Erikson, E. H. (1993). Identität und Lebenszyklus: drei Aufsätze [Identity and Lifecycle: Three Essays]. Translated by K. Hügel, Vol. 1. Frankfurt Main: Suhrkamp.

Fthenakis, W. E., and Minsel, B. (2002). Die Rolle des Vaters in der Familie. [The Role of Fathers Within the Family]. Band 213. Schriftenreihe des Bundesministeriums für Familie, Senioren, Frauen und Jugend. Stuttgart; Berlin; Köln: Kohlhammer.

Gunderson, E. A., Ramirez, G., Levine, S. C., and Beilock, S. L. (2012). The role of parents and teachers in the development of gender-related math attitudes. Sex Roles 66, 153-166. doi: 10.1007/s11199-011-9996-2.144

Halim, L., Rahmann, N. A., Zamri, R., and Mohtar, L. (2018). The roles of parents in cultivating children's interest towards science learning and careers. Kasetsart J. Soc. Sci. 39, 190-116. doi: 10.1016/j.kjss.2017.05.001

Hawkins, A. J., and Dollahite, D. C. (1997). Generative Fathering: Beyond the Deficit Perspective. Thousand Oaks, CA: Sage.

Hu, L. T., and Bentler, P. M. (1999). Cutoff criteria for fit indexes in covariance structural analysis: conventional criteria versus new alternatives. Struct. Equat. Model. 6, 51-55. doi: 10.1080/10705519909540118

Kan, M. Y., Sullivan, O., and Gershuny, J. (2011). Gender convergence in domestic work: discerning the effects of interactional and institutional barriers from large-scale data. Sociology 45, 234-225.doi: 10.1177/0038038510394014

Kerney, A. T., and YourLife Campaign (2016). Tough Choices: The Real Reasons A-level Students are Steering Clear of Science and Maths. Available online at: https://www.atkearney.com/documents/10192/7390617/Tough+Choices.pdf

Leaper, C., Farkas, T., and Brown, C. S. (2011). Adolescent girls' experiences and gender-related beliefs in relation to their motivation in math/science and English. J. Youth Adolesc. 41, 268-282. doi: 10.1007/s10964-011-9693-Z

Leff, S. S., and Hoyle, R. H. (1995). Young athletes' perceptions of parental support and pressure. J. Youth Adolesc. 24, 187-203. doi: 10.1007/BF015 37149

Levpušček, M. P., and Zupančič, M. (2009). Math achievement in early adolescence: the role of parental involvement, teacher's behavior, and students' motivational beliefs about math. J. Early Adolesc. 29, 541-570. doi: 10.1177/0272431608324189

Little, T. D., Cunningham, W. A., Shahar, G., and Widaman, K. F. (2002). To parcel or not to parcel: exploring the question and weighing the merits. Struct. Equat. Model. 9, 151-173. doi: 10.1207/S15328007SEM0902_1.

Little, T. D., Rhemtulla, M., Gibson, K., and Schoemann, A. M. (2013). Why the items versus parcels controversy needn't be one. Psychol. Methods 18, 285-300. doi: $10.1037 / \mathrm{a} 0033266$

Lubinski, D., Benbow, C. P., Shea, D. L., Eftekhari-Sanjani, H., and Halvorson, M. B. (2001). Men and women at promise for scientific excellence: similarity not dissimilarity. Psychol. Sci. 12, 309-317. doi: 10.1111/1467-9280.00357

Lytton, H., and Romney, D. M. (1991). Parents' differential socialization of boys and girls: a meta-analysis. Psychol. Bull. 109, 267-296. doi: 10.1037/0033-2909.109.2.267

Mallers, M. H., Charles, S. T., Neupert, S. D., and Almeida, D. M. (2010). Perceptions of childhood relationships with mother and father: daily emotional and stressor experiences in adulthood. Dev. Psychol. 46, 1651-1661.doi: 10.1037/a0021020

Mann, A., and DiPrete, T. A. (2013). Trends in gender segregation in the choice of science and engineering majors. Soc. Sci. Res. 42, 1519-1541. doi: 10.1016/j.ssresearch.2013.07.002

Marks, L., and Palkovitz, R. (2004). American fatherhood types: the good, the bad, and the uninterested. Fathering 2, 113-129. doi: 10.3149/fth.0202.113

Mullis, I. V. S., Martin, M. O., Foy, P., and Hooper, M. (2016). TIMSS Advanced 2015 International Results in Advanced Mathematics and Physics. Boston College, TIMSS \& PIRLS International Study Center. Available online at: http:// timssandpirls.bc.edu/timss2015/international-results/advanced/

Muthén, L. K., and Muthén, B. O. (1998-2013). Mplus User's Guide, 7th Edn. Los Angeles, CA: Muthén \& Muthén.

Nasser, F., and Wisenbaker, J. (2003). A Monte Carlo study investigating the impact of item parceling on measures of fit in confirmatory factor analysis. Educ. Psychol. Measure. 63, 729-757. doi: 10.1177/0013164403258228

National Science Board (2014). Science and Engineering Indicators 2014. Arlington VA: National Science Foundation (NSB 14-01).

Nawrotzki, K. D. (2012). "Parent-school relations in England and the USA: Partnership, problematized," in The Politicization of Parenthood: Shifting
Private and Public Responsibilities in Education and Child Rearing, eds M. Richter \& S. Andresen (Dordrecht: Springer), 69-83.

Paa, H. K., and Hawley McWhirter, E. (2011). Perceived influences on high school students' current career expectations. Career Dev. Q. 49, 29-44. doi: 10.1002/j.2161-0045.2000.tb00749.x

Raufelder, D., Jagenow, D., Drury, K., and Hoferichter, F. (2013). Social Relationships and Motivation in Secondary School: 4 different motivation types. Learn. Individ. Diff. 24, 89-95. doi: 10.1016/j.lindif.2012.12.002

Reinking, A., and Martin, B. (2018). The gender gap in STEM fields: theory, movements, and ideas to engage girls in STEM. J. N. Approaches Educ. Res. 7, 148-153. doi: 10.7821/naer.2018.7.271

Reitzle, M., Metzke, C. W., and Steinhausen, H.-C. (2001). Eltern und kinder: der Zürcher kurzfragebogen zum erziehungsverhalten (ZKE). [Parents and children: the Zürich questionnaire of educational behavior (ZKE)]. Diagnostica 47, 196-207. doi: 10. 1026//0012-1924.47.4.196.

Robnett, R. D., and Leaper, C. (2013). Friendship groups, personal motivation, and gender in relation to high school students' STEM career interest. J. Res. Adolesc. 23, 652-664. doi: 10.1111/jora.12013

Rozek, C. S., Hyde, J. S., Svoboda, R. C., Hulleman, C. S., and Harackiewicz, J. M. (2015). Gender differences in the effects of a utility-value intervention to help parents motivate adolescents in mathematics and science. J. Educ. Psychol. 107, 195-206. doi: 10.1037/a0036981

Saracho, O. L., and Spodek, B. (2008). Fathers: the 'invisible’ parents. Early Child Dev. Care 178, 821-836, doi: 10.1080/03004430802352244

Satorra, A., and Bentler, P. M. (2001). A scaled difference Chi square test statistic for moment structure analysis. Psychometrika 66, 507-514. doi: 10.1007/BF02296192.

Simpkins, S. D., Price, C. D., and Garcia, K. (2015). Parental support and high school students' motivation in biology, chemistry, and physics: understanding differences among Latino and Caucasian boys and girls. J. Res. Sci. Teach. 52, 1386-1407. doi: 10.1002/tea.21246

Su, R., and Rounds, J. (2015). All STEM fields are not created equal: people and things interests explain gender disparities across STEM fields. Front. Psychol. 6:189. doi: 10.3389/fpsyg.2015.00189

United Nations Educational Scientific and Cultural Organization (2017). Cracking the Code: Girls' and Women's Education in Science, Technology, Engineering and Mathematics (STEM). Education 2030. Paris. Available online at: http:// unesdoc.unesco.org/images/0025/002534/253479E.pdf

Valla, J. M., and Ceci, S. J. (2014). Breadth-based models of women's underrepresentation in STEM fields: an integrative commentary on Schmidt (2011) and Nye et al. (2012). Perspect. Psychol. Sci. 9, 219-224. doi: 10.1177/1745691614522067

van Hoorn, J., van Dijk, E., Meuwese, R., Rieffe, C., and Crone, E. A. (2014). Peer influence on prosocial behavior in adolescence. J. Res. Adolesc. 26, 90-100.doi: 10.1111/jora.12173

Wijsman, L. A., Warrens, M. J., Saab, N., van Driel, J. H., and Westenberg, P. M. (2016). Declining trends in student performance in lower secondary education. Eur. J. Psychol. Educ. 31, 595-612. doi: 10.1007/s10212-015-0277-2

Winquist Nord, C., and West,. J. (2001). Fathers' and Mothers' Involvement in Their Children's Schools by Family Type and Resident Status, NCES 2001-032. Washington, DC: U.S. Department of Education. National Center for Education Statistics. Available online at: https://nces.ed.gov/pubs2001/ 2001032.pdf

Yuan, K.-H., and Bentler, P. M. (2004). On Chi square difference and z-tests in mean and covariance structure analysis when the base model is misspecified. Educ. Psychol. Measure. 64, 737-757. doi: 10.1177/0013164404264853

Conflict of Interest Statement: The authors declare that the research was conducted in the absence of any commercial or financial relationships that could be construed as a potential conflict of interest.

Copyright (C) 2019 Hoferichter and Raufelder. This is an open-access article distributed under the terms of the Creative Commons Attribution License (CC BY). The use, distribution or reproduction in other forums is permitted, provided the original author(s) and the copyright owner(s) are credited and that the original publication in this journal is cited, in accordance with accepted academic practice. No use, distribution or reproduction is permitted which does not comply with these terms. 